\title{
A Fuzzy Multiplicative Performance Indicator to Measure Circular Economy Efficiency
}

\author{
Mohamed El Alaoui \\ Department of Production and Industrial Engineering, \\ ENSAM Moulay Ismail University, Meknes, Morocco. \\ E-mails: mohamed.elalaoui@edu.umi.ac.ma ,mohamedelalaoui208@gmail.com
}

(Received November 1, 2019; Accepted June 2, 2020)

\begin{abstract}
In a world where the linear economy has already proven its limits. Sustainable development through circular economy becomes a necessity more than a choice. To verify the adequacy between a sustainable development objective and the related management of operations, a variety of performance indicators exist in the literature and an overall is required to ease comparisons. Here we use an extended fuzzy weighted product to avoid overvaluation of an indicator over the others. To handle qualitative aspects, fuzzy logic is used to shorten the gap between humans' perception and machine language. These qualitative features require various evaluators to reduce bias. Thus, a coherence measure is adapted.
\end{abstract}

Keywords- Circular economy (CE), Multi-criteria decision making (MCDM), Fuzzy consensus, Fuzzy weighted product.

\section{Introduction}

Human impacts on earth have become so obvious since the Industrial Revolution that some scientists are talking about a new geological era called Anthropocene (Ellis, 2018). Facing the climate urgency, humanity is forced to implement sustainable practices. However, the economic models used are based on consumption in a linear pattern; which consists of producing consumer goods from raw materials that will be discarded at the end of their life cycle; this model of thought including the entire supply chain and the related operations management, has to be replaced by a circular economy scheme. Unfortunately, the multiplicity of definitions leads us to irreconcilable practices. Section 2 will be devoted to clarify definitions.

To make sure that the management of operations aligns with a sustainable perspective. Adequate measures need to be used. A review of 1,803 measurement scales from 230 published articles was proposed in (Roth et al., 2008). However, what to measure? And how measuring it? According to (EASAC, 2016) more than 300 Performance Indicators (PI) of circular economy exist. Furthermore, trying to measure the overall performance, the economic aspect is carving the lion's share, which calls into question the whole process. Here, it is proposed in Section 3, a multiplicative aggregation to avoid the dominance of one aspect over the others.

These performance indicators can be classified into two broad categories, objective and subjective. While the former reflects a measure taken. The latter depends heavily on the appreciation of the people implementing them. It is for this reason that the process includes several persons, in order to minimize the bias of judgments. Section 4 includes an adapted consensus-building process. 
International Journal of Mathematical, Engineering and Management Sciences

Vol. 5, No. 6, 1118-1127, 2020

https://doi.org/10.33889/IJMEMS.2020.5.6.085

The expression of these judgments is clearly more suitable using linguistic variables than with numbers. Fuzzy logic, in addition to facilitating the understanding of human language, can incorporate both qualitative and quantitative data.

In the sequel. A consensual approach based on fuzzy logic to measure the overall performance of $\mathrm{CE}$ is proposed. Thus, in section 2, we review some close definitions and approaches in addition to our perspective to CE. Section 3 contains the extended fuzzy weighted multiplication and the required fuzzy logic background. Section 4 presents the adapted consensus measure. Section 5 portrays an illustrative example, while Section 6 concludes this paper.

\section{Definitions}

Circular Economy (CE) receives unprecedented growing attention. However, with more than 114 definitions (Kirchherr et al., 2017) and a plethora of sound alike words; even for initiated persons; such as sustainability (Fuller, 2010), sustainable development (Giddings et al., 2002), bio and green economy (Ferreira Gregorio et al., 2018). Clarification is needed.

Wanting to be exhaustive, authors tend to develop long definitions, which are hardly memorized. Here, a simple one is retained where the details explained in others will result "one, where the resources coming into the economy are not allowed to become waste or lose their value" (Benton et al., 2017). It can be inferred from this definition that:

- In contrast to authors who believe that, the CE does not require closed loop (Howard et al., 2019). The abolition of waste, requires its reuse and thus to close the loop.

- Furthermore, the prohibition of degradation between each reuse, invokes not only cycling, but also upcycling. Obliging stakeholders to match the technical and the biological cycles (Jørgensen and Pedersen, 2018). A circularity metric taking into consideration upcycling was introduced in (Figge et al., 2018).

This distinction between upcycling and recycling challenges several things. Let us consider soft drinks sold in plastic bottles as an example. The latter; plastic bottles; are only recyclable in "downcycling". Despite all the promises made, it seems that we are always far from the count, and especially late. Advertisements advocating a lighter weight compared to the glass bottle, prompted the consumer to adopt what manufacturers want. Note that glass bottles are reusable and require manufacturers to manage the return chain of empty bottles. This calls into question our will, citizens of the world, to change our habits. As well as the willingness of the media and the competent authorities to regulate the messages conveyed. The mission is all the more difficult in the presence of climate-septic governments.

Further discussion clarifying the distinction between Green Economy, Bio Economy and CE could be found in (D'Amato et al., 2017, 2019; Ferreira Gregorio et al., 2018). And between Green Supply Chain Management, Sustainable Supply Chain Management, Environmental Supply Chain Management and Closed Loop Supply Chains (Farooque et al., 2019).

What to measure is all the more debatable. A series of national (Geng et al., 2012, 2013) regional (Avdiushchenko and Zając, 2019; Smol et al., 2017; Tantau et al., 2018) and industry based measures (Molina-Sánchez et al., 2018) were proposed. It is true that national or regional policy and related indicators could be seen as a step in the right way. However, are they enough when 
International Journal of Mathematical, Engineering and Management Sciences

Vol. 5, No. 6, 1118-1127, 2020

https://doi.org/10.33889/IJMEMS.2020.5.6.085

Supply Chains are involving several countries and regions? To avoid any emissions due to transportation and logistics, it seems that the only true CE can only be local.

In order to achieve the CE, two approaches exist in the literature. The Rs approach and the ReSOLVE approach. While ReSOLVE contains (Regenerate, Share, Optimize, Loop, Virtualize and Exchange) (Lopes de Sousa Jabbour et al., 2019). Various Rs frameworks exist in the literature, varying from 3Rs (Xuan et al., 2011), 4Rs (Hu et al., 2011), 6Rs (Sihvonen and Ritola, 2015) and even 9Rs (Potting et al., 2017). The last includes (refuse, rethink, reduce, reuse, repair, refurbish, remanufacture, repurpose, recycle and recover).

\section{Performance Indicators}

In the 3Rs approach used in Geng et al. (2012), the authors maintained that the Chinese CE indicators overvalued reuse and recycle over reduce. Thus, how to formulate an overall performance indicator while avoiding the predominance of one aspect over the rest?

Mathematically speaking, the Weighted Average Mean (WAM) is frequently used due its simplicity. However, its compensatory nature is not desirable in this context. This is all the more alarming when strong economic results mask poor ecological performance. The Weighted Product Mean (WPM) on the other side imposes a simultaneous considerations of all entry elements. However, if one of them is dysfunctional, it does not mean that the whole system is dysfunctional systematically. In order to include all aspects, while avoiding the aforementioned problems, we will adapt the formula proposed in El Alaoui and Ben-Azza (2017b):

$P I_{O}=\frac{\prod_{i=1}^{n}\left(P I_{i}+w_{i}\right)^{1 / n}-\prod_{i=1}^{n} w_{i}^{1 / n}}{\prod_{i=1}^{n}\left(1+w_{i}\right)^{1 / n}-\prod_{i=1}^{n} w_{i}^{1 / n}}$

where $w_{i}$ represents the weight of the $i^{t h} \mathrm{PI}: P I_{i}$. The weights are inversely proportional to PI's importance. $n$ the number of PIs. And $P I_{O}$ the overall performance.

PIs could be divided into two main categories, quantitative ones and qualitative ones (El Alaoui and Ben-Azza, 2017a). With regard to quantitative indicators, the difficulty lies mainly in the normalization step. Since it requires merging values with different units. In the following, the data is considered to be normalized in the unity interval $[0,1]$.

Qualitative indicators are more difficult to capture. Fuzzy logic (Zadeh, 1965), seems to be the perfect tool to handle such situations, since it permits capturing human judgements and handling both quantitative and qualitative data. For computational reasons, the frequently used notation is based on trapezoidal Fuzzy Numbers FNs denoted by 4-tuple $\tilde{A}\left(a^{1}, a^{2}, a^{3}, a^{4}\right)$ (El Alaoui, 2018). If $a^{2}=a^{3}$ then the trapezoidal FN becomes a triangular FN. If $a^{1}=a^{2}=a^{3}=a^{4}$ then we have a classical crisp number. Thus, crisp numbers are considered as a special case.

\section{Consensus}

The qualitative assessments depend mainly on the evaluator. Thus, the process involves several Decision Makers (DM) in order to reduce bias. Since full and unanimous consensus is rarely achieved, a fuzzy soft measure would be more appropriate (Herrera-Viedma et al., 2014). However, first what is the consensus? It has various meaning and utilization (Briggs, 2013) varying from philosophy and mathematics (Lehrer and Wagner, 1981) to design (Day and Parnell, 2003) and CE 
International Journal of Mathematical, Engineering and Management Sciences

Vol. 5, No. 6, 1118-1127, 2020

https://doi.org/10.33889/IJMEMS.2020.5.6.085

(Prieto-Sandoval et al., 2018), or even as a measure of sustainability (Bender and Simonovic, 1997), making consensus on consensus barely achievable (Cook et al., 2016). In the fuzzy context, it is usually linked to similarity measures (López-Ortega and Castro-Espinoza, 2019). It should be noted that by consensus, it is suggested here, the aggregation of several opinions into the one that may fit all participants (El Alaoui et al., 2019a). In that sense, we will use the improved version of Lee's algorithm (Lee, 2002) proposed in El Alaoui et al. (2019b) aiming to minimize weighted incoherencies:

$\min \sum_{k=1}^{K} w_{k}^{t} *\left(c-S\left(\widetilde{R}_{k}, \tilde{R}\right)\right)$,

where $w_{k}$ are the decisions weights, verifying $w_{k} \geq 0$ and $\sum_{k=1}^{K} w_{k}=1 . t \in I N^{*} \backslash\{1\}, c \in$ $\left[1,+\infty\left[, \widetilde{R}_{k}\right.\right.$ expressed opinions, $\tilde{R}$ the consensus to be achieved, $K$ the number of DMs involved and $S\left(\tilde{R}_{k}, \tilde{R}\right)$ the similarity than can computed by:

$S\left(\tilde{R}_{k}, \tilde{R}\right)=1-\frac{1}{4}\left(\sum_{q=1}^{4}\left(\left|r_{k}^{q}-r^{q}\right|\right)^{P}\right)^{\frac{1}{p}}$

\section{Illustrative Example}

This example proposed (Zhao et al., 2017), combining quantitative and qualitative criteria. 4 DMs are to evaluate 6 alternatives in accordance to 9 subjective indicators. In addition, the DMs have to estimate all 26 indicators weights. To ease comparison, we adopt the same linguistic variables for weights and alternatives assessments (Table 1).

Table 1. Linguistic variables for weights and alternatives assessments

\begin{tabular}{|c|c|c|c|}
\hline Linguistic variable & Fuzzy number & Linguistic variable & Fuzzy number \\
\hline Very Poor $(\mathrm{VP})$ & $(0,0,0.2)$ & Very Low $(\mathrm{VL})$ & $(0,0,0.3)$ \\
\hline Poor $(\mathrm{P})$ & $(0,0.2,0.4)$ & Low $(\mathrm{L})$ & $(0,0.3,0.5)$ \\
\hline Fair $(\mathrm{F})$ & $(0.3,0.5,0.7)$ & Medium $(\mathrm{M})$ & $(0.2,0.5,0.8)$ \\
\hline Good $(\mathrm{G})$ & $(0.6,0.8,1)$ & High $(\mathrm{H})$ & $(0.7,1)$ \\
\hline Very Good $(\mathrm{VG})$ & $(0.8,1,1)$ & Very High $(\mathrm{VH})$ & $1,1)$ \\
\hline
\end{tabular}

The evaluations of indicators weights by the $4 \mathrm{DMs}$ in addition to their nature (quantitative/qualitative) (Max/min) and the consensual assessments are given in Table 2.

To avoid further discussions due to normalization, we use the normalized measures presented in Zhao et al. (2017) (Table 3).

Table 4 contains the individual assessments according to each subjective indicator

While the weights of the performance indicators to be minimized will remain as is, the others will be reversed to be adapted to the formula used (Eq. 1). 
International Journal of Mathematical, Engineering and Management Sciences

Vol. 5, No. 6, 1118-1127, 2020

https://doi.org/10.33889/IJMEMS.2020.5.6.085

The Table 5 resumes the consensual evaluations (Eq. 2-3) for the 6 alternatives in accordance to the subjective indicators, in addition to the overall evaluations (Eq. 1)

Table 2. Indicators individual evaluations, nature and collective assessments

\begin{tabular}{|c|c|c|c|c|c|c|c|}
\hline Indicator & $\begin{array}{l}\text { Quantitative } \\
\text { /qualitative }\end{array}$ & Max/min & DM1 & DM2 & DM3 & DM4 & Aggregated assessment \\
\hline I1 & Quantitative & $\max$ & High & High & Medium & Medium & $(0.35,0.6,0.9)$ \\
\hline $\mathrm{I} 2$ & Quantitative & $\max$ & High & Medium & High & High & $(0.430,0.653,0.953)$ \\
\hline I3 & Quantitative & $\max$ & Medium & Medium & High & Medium & $(0.270,0.547,0.847)$ \\
\hline $\mathrm{I} 4$ & Quantitative & $\max$ & Low & Low & Low & V Low & $(0,0.229,0.452)$ \\
\hline I5 & qualitative & $\max$ & Medium & High & Medium & Medium & $(0.270,0.547,0.847)$ \\
\hline I6 & Quantitative & Min & High & High & High & Medium & $(0.430,0.653,0.953)$ \\
\hline I7 & Quantitative & Min & Medium & High & High & Medium & $(0.35,0.6,0.9)$ \\
\hline I8 & Quantitative & $\max$ & High & High & High & High & $(0.5,0.7,1)$ \\
\hline I9 & Quantitative & $\max$ & Medium & Medium & High & High & $(0.35,0.6,0.9)$ \\
\hline $\mathrm{I} 10$ & Quantitative & $\max$ & High & High & High & High & $(0.5,0.7,1)$ \\
\hline I11 & qualitative & $\max$ & Medium & Medium & High & High & $(0.35,0.6,0.9)$ \\
\hline I12 & Quantitative & Min & High & High & High & Medium & $(0.430,0.653,0.953)$ \\
\hline $\mathrm{I} 13$ & Quantitative & Min & High & Medium & High & Medium & $(0.35,0.6,0.9)$ \\
\hline I14 & Quantitative & Min & High & High & High & Medium & $(0.430,0.653,0.953)$ \\
\hline $\mathrm{I} 15$ & Quantitative & $\max$ & High & High & High & High & $(0.5,0.7,1)$ \\
\hline I16 & Quantitative & $\max$ & High & High & High & High & $(0.5,0.7,1)$ \\
\hline I17 & Quantitative & $\max$ & High & High & High & High & $(0.5,0.7,1)$ \\
\hline $\mathrm{I} 18$ & qualitative & $\max$ & High & High & High & High & $(0.5,0.7,1)$ \\
\hline I19 & qualitative & $\max$ & Medium & Medium & High & Medium & $(0.270,0.547,0.847)$ \\
\hline $\mathrm{I} 20$ & qualitative & $\max$ & Medium & High & High & Medium & $(0.35,0.6,0.9)$ \\
\hline $\mathrm{I} 21$ & Quantitative & $\max$ & Medium & Medium & High & High & $(0.35,0.6,0.9)$ \\
\hline $\mathrm{I} 22$ & qualitative & $\max$ & Medium & Medium & High & High & $(0.35,0.6,0.9)$ \\
\hline $\mathrm{I} 23$ & qualitative & $\max$ & Medium & High & Medium & Medium & $(0.270,0.547,0.847)$ \\
\hline I24 & qualitative & $\max$ & Medium & High & Medium & Medium & $(0.270,0.547,0.847)$ \\
\hline $\mathrm{I} 25$ & qualitative & $\max$ & Medium & High & High & Medium & $(0.35,0.6,0.9)$ \\
\hline $\mathrm{I} 26$ & Quantitative & $\max$ & Medium & Medium & Medium & High & $(0.270,0.547,0.847)$ \\
\hline
\end{tabular}

Table 3. Normalized quantitative assessments

\begin{tabular}{|c|c|c|c|c|c|c|}
\hline Indicator & $\mathbf{A 1}$ & $\mathbf{A 2}$ & $\mathbf{A 3}$ & $\mathbf{A 4}$ & $\mathbf{A 5}$ & $\mathbf{A 6}$ \\
\hline I1 & 0.15949 & 0.07407 & 0.24958 & 0.24394 & 0.21496 & 0.05797 \\
\hline I2 & 0.21742 & 0.21212 & 0.19697 & 0.17424 & 0.18939 & 0.00985 \\
\hline I3 & 0.20549 & 0.24631 & 0.19704 & 0.21675 & 0.09923 & 0.03519 \\
\hline I4 & 0.18479 & 0.15529 & 0.13976 & 0.28061 & 0.14162 & 0.09793 \\
\hline I6 & 0.12228 & 0.20380 & 0.12738 & 0.24456 & 0.14912 & 0.15285 \\
\hline I7 & 0.14980 & 0.17174 & 0.33371 & 0.15898 & 0.15131 & 0.03446 \\
\hline I8 & 0.18292 & 0.16781 & 0.18909 & 0.17984 & 0.13647 & 0.14387 \\
\hline I9 & 0.16393 & 0.11241 & 0.07728 & 0.19672 & 0.09836 & 0.35129 \\
\hline I10 & 0.17978 & 0.17127 & 0.18945 & 0.16180 & 0.13145 & 0.16625 \\
\hline I12 & 0.19064 & 0.19064 & 0.11255 & 0.31139 & 0.12292 & 0.07186 \\
\hline I13 & 0.17669 & 0.22087 & 0.29449 & 0.17669 & 0.12621 & 0.00505 \\
\hline I14 & 0.17707 & 0.27826 & 0.14428 & 0.16232 & 0.19478 & 0.04328 \\
\hline I15 & 0.17584 & 0.17407 & 0.17762 & 0.17052 & 0.16874 & 0.13321 \\
\hline I16 & 0.17331 & 0.17331 & 0.16464 & 0.16811 & 0.15598 & 0.16464 \\
\hline I17 & 0.17422 & 0.16899 & 0.17422 & 0.17247 & 0.17073 & 0.13937 \\
\hline I21 & 0.19280 & 0.18123 & 0.17138 & 0.12725 & 0.14996 & 0.17738 \\
\hline I26 & 0.36611 & 0.34728 & 0.06485 & 0.12343 & 0.07950 & 0.01883 \\
\hline
\end{tabular}


International Journal of Mathematical, Engineering and Management Sciences

Vol. 5, No. 6, 1118-1127, 2020

https://doi.org/10.33889/IJMEMS.2020.5.6.085

Table 4. Individual assessments in accordance to the subjective indicators

\begin{tabular}{|c|c|c|c|c|c|c|c|c|c|c|}
\hline DMs & Alternative & I5 & I11 & I18 & I19 & I20 & I22 & I23 & I24 & $\mathbf{I 2 5}$ \\
\hline \multirow{6}{*}{ DM1 } & A1 & Good & Good & Good & Good & Good & Good & Good & Good & Good \\
\hline & $\mathrm{A} 2$ & Fair & Good & Fair & Good & Good & Good & Good & Fair & Good \\
\hline & A3 & Good & Fair & VG & Fair & Fair & Good & Fair & Fair & Fair \\
\hline & A4 & VG & Fair & Good & Fair & Fair & Good & Fair & Fair & Good \\
\hline & A5 & Good & Good & Poor & Poor & Good & Fair & Fair & Fair & Fair \\
\hline & A6 & Fair & Poor & Fair & Fair & VP & Fair & Fair & Fair & Poor \\
\hline \multirow{6}{*}{ DM2 } & A1 & VG & Good & Good & Good & Good & Good & Good & Good & Good \\
\hline & A2 & Good & Fair & Fair & Fair & VG & Good & Fair & Fair & Fair \\
\hline & A3 & Good & Fair & Good & Good & Fair & Fair & Good & Fair & Fair \\
\hline & A4 & VG & Fair & Fair & Good & Fair & Fair & Fair & Fair & Good \\
\hline & A5 & Good & Good & VP & Poor & Fair & Poor & Fair & Fair & Fair \\
\hline & A6 & Fair & Poor & Poor & Fair & Poor & Poor & Poor & Poor & Fair \\
\hline \multirow{6}{*}{ DM3 } & A1 & Good & Good & Good & VG & Good & Good & Good & Good & Good \\
\hline & A2 & Good & Good & Fair & Fair & Good & Fair & Fair & Fair & Good \\
\hline & A3 & Good & Fair & Good & Fair & Poor & Fair & Fair & Fair & Fair \\
\hline & A4 & $\mathrm{VG}$ & Fair & Fair & Good & Good & Good & Good & Fair & Fair \\
\hline & A5 & Good & Good & VP & Fair & Good & Poor & Good & Fair & Fair \\
\hline & A6 & Fair & Poor & Poor & Poor & Poor & Poor & Fair & Fair & Poor \\
\hline \multirow{6}{*}{ DM4 } & A1 & Good & Fair & Good & Good & Good & Good & Good & Good & VG \\
\hline & A2 & Good & Fair & Fair & Fair & Good & Fair & Fair & Fair & Good \\
\hline & A3 & Good & Fair & Good & Good & Fair & Fair & Fair & Fair & Fair \\
\hline & A4 & Good & Fair & Fair & Good & Fair & Good & Fair & Fair & Fair \\
\hline & A5 & Good & Good & VP & Poor & Fair & Fair & Fair & Fair & Fair \\
\hline & A6 & Fair & Fair & Poor & Poor & Poor & Poor & Fair & Fair & Fair \\
\hline
\end{tabular}

Three main approach exist to rank FN, the most accurate in this situation is by using a ranking function mapping the FN to the real line. While several ranking functions exist in the literature (El Alaoui et al., 2018; Wu and Mendel, 2009), we adopt the one used in Zhao et al. (2017) for triangular FN $\tilde{A}\left(a^{1}, a^{2}, a^{3}\right)$ to ease comparison: $\mathcal{R}(\tilde{A})=\left(a^{1}+4 * a^{2}+a^{3}\right) / 6$.

It is true that the final ranking (Table 5) remains the same as in Zhao et al. (2017). However, the gap between the final scores changes mainly due to several reasons:

The opinions aggregation in Zhao et al. (2017) consist of a simple WAM, while the coherence measure proposed tends to be closer to the consensus.

In Zhao et al. (2017) the authors proceed to early defuzzification, which results on information loss. While in the proposed it is realized till the end for the final ranking. This is possible, thanks to the aggregation formula used that permits simultaneous handling of both fuzzy and crisp data, in addition, to avoid aspiration by extrema values. 
International Journal of Mathematical, Engineering and Management Sciences

Vol. 5, No. 6, 1118-1127, 2020

https://doi.org/10.33889/IJMEMS.2020.5.6.085

Table 5. Consensual subjective evaluations, overall fuzzy, defuzzified evaluations, and final rank

\begin{tabular}{|c|c|c|c|c|c|c|}
\hline Indicators & A1 & A2 & $\mathbf{A 3}$ & A4 & A5 & A6 \\
\hline I5 & $\begin{array}{c}(0.648,0.848 \\
, 1)\end{array}$ & $\begin{array}{c}(0.533,0.733 \\
0.933)\end{array}$ & $(0.6,0.8,1)$ & $\begin{array}{c}(0.752,0.952 \\
1)\end{array}$ & $(0.6,0.8,1)$ & $(0.3,0.5,0.7)$ \\
\hline I11 & $\begin{array}{c}0.533,0.73 \\
0.93)\end{array}$ & $\begin{array}{c}(0.45,0.65 \\
0.85)\end{array}$ & $(0.3,0.5,0.7)$ & $(0.3,0.5,0.7)$ & $(0.6,0.8,1)$ & $\begin{array}{c}(0.067,0.267, \\
0.467)\end{array}$ \\
\hline I18 & $(0.6,0.8,1)$ & $(0.3,0.5,0.7)$ & $\begin{array}{c}(0.648,0.848 \\
, 1) \\
\end{array}$ & $\begin{array}{c}(0.367,0.567 \\
0.767)\end{array}$ & $\begin{array}{c}(0,0.048 \\
0.248) \\
\end{array}$ & $\begin{array}{c}(0.067,0.267, \\
0.467)\end{array}$ \\
\hline I19 & $\begin{array}{c}(0.648,0.848 \\
, 1)\end{array}$ & $\begin{array}{c}(0.367,0.567 \\
0.767)\end{array}$ & $\begin{array}{c}(0.45,0.65 \\
0.85)\end{array}$ & $\begin{array}{c}(0.533,0.733 \\
0.933)\end{array}$ & $\begin{array}{c}(0.067,0.267 \\
0.467)\end{array}$ & $\begin{array}{c}(0.15,0.35 \\
0.55)\end{array}$ \\
\hline $\mathrm{I} 20$ & $(0.6,0.8,1)$ & $\begin{array}{c}(0.648,0.848, \\
1)\end{array}$ & $\begin{array}{c}(0.233,0.433, \\
0.633)\end{array}$ & $\begin{array}{c}(0.367,0.567, \\
0.767)\end{array}$ & $\begin{array}{c}(0.45,0.65 \\
0.85)\end{array}$ & $\begin{array}{c}(0,0.152, \\
0.352)\end{array}$ \\
\hline $\mathrm{I} 22$ & $(0.6,0.8,1)$ & $\begin{array}{c}(0.45,0.65 \\
0.85) \\
\end{array}$ & $\begin{array}{c}(0.367,0.567 \\
0.767)\end{array}$ & $\begin{array}{c}(0.533,0.73 \\
0.93)\end{array}$ & $\begin{array}{c}(0.15,0.35 \\
0.55) \\
\end{array}$ & $\begin{array}{c}(0.067,0.267, \\
0.467)\end{array}$ \\
\hline $\mathrm{I} 23$ & $(0.6,0.8,1)$ & $\begin{array}{c}(0.367,0.567, \\
0.767)\end{array}$ & $\begin{array}{c}(0.367,0.567, \\
0.767)\end{array}$ & $\begin{array}{c}(0.367,0.567, \\
0.767)\end{array}$ & $\begin{array}{c}(0.367,0.567 \\
0.767)\end{array}$ & $\begin{array}{c}(0.233,0.433 \\
0.633)\end{array}$ \\
\hline $\mathrm{I} 24$ & $(0.6,0.8,1)$ & $(0.3,0.5,0.7)$ & $(0.3,0.5,0.7)$ & $(0.3,0.5,0.7)$ & $(0.3,0.5,0.7)$ & $\begin{array}{c}(0.233,0.433, \\
0.633)\end{array}$ \\
\hline I 25 & $\begin{array}{c}(0.648,0.848 \\
, 1) \\
\end{array}$ & $\begin{array}{c}(0.533,0.733, \\
0.933) \\
\end{array}$ & $(0.3,0.5,0.7)$ & $\begin{array}{c}(0.45,0.65 \\
0.85) \\
\end{array}$ & $(0.3,0.5,0.7)$ & $\begin{array}{c}(0.15,0.35 \\
0.55) \\
\end{array}$ \\
\hline $\begin{array}{l}\text { Overall } \\
\text { evaluation }\end{array}$ & $\begin{array}{c}0.196,0.476, \\
1) \\
\end{array}$ & $\begin{array}{c}0.183,0.461, \\
0.981) \\
\end{array}$ & $\begin{array}{c}(0.179,0.454 \\
0.972)\end{array}$ & $\begin{array}{c}(0.183,0.461, \\
0.980) \\
\end{array}$ & $\begin{array}{c}(0.083,0.434 \\
0.974) \\
\end{array}$ & $\begin{array}{c}0.143,0.411, \\
0.915) \\
\end{array}$ \\
\hline $\begin{array}{l}\text { Defuzzified } \\
\text { evaluation }\end{array}$ & 0.5369 & 0.5216 & 0.5147 & 0.5214 & 0.4743 & 0.4704 \\
\hline Rank & 1 & 2 & 4 & 3 & 5 & 6 \\
\hline
\end{tabular}

\section{Conclusion}

This paper presents a fuzzy mathematical methodology to build an overall PI for CE. While fuzzy logic is used as a powerful tool that permits handling quantitative and qualitative quantities. The last, qualitative aspects need numerous decision-makers to reduce bias. Hence, a fuzzy coherence measure was adapted.

$\mathrm{CE}$ as a tool to reach sustainability requires simultaneous consideration for different aspects. To do so, an extended fuzzy weighted multiplication was proposed to avoid the overvaluation and drawbacks of classical operators. The merits of the proposed method were proven in an illustrative example.

Conflict of Interest

The authors confirm that there is no conflict of interest to declare for this publication.

\section{Acknowledgment}

This research did not receive any specific grant from funding agencies in the public, commercial, or not-for-profit sectors.

The authors sincerely appreciate the editor and reviewers for their time and valuable comments.

\section{References}

Avdiushchenko, A., \& Zając, P. (2019). Circular economy indicators as a supporting tool for European regional development policies. Sustainability, 11(11), 3025. 
International Journal of Mathematical, Engineering and Management Sciences

Vol. 5, No. 6, 1118-1127, 2020

https://doi.org/10.33889/IJMEMS.2020.5.6.085

Bender, M.J., \& Simonovic, S.P. (1997). Consensus as the measure of sustainability. Hydrological Sciences Journal, 42(4), 493-500.

Benton, D., Hazell, J., \& Hill, J. (2017). The guide to the circular economy: capturing value and managing material risk. Routledge. https://doi.org/10.4324/9781351274364

Briggs, B. (2013). Introduction to consensus. BookBaby. eBook ISBN:9780989259507. https://store.bookbaby.com/book/introduction-to-consensus.

Cook, J., Oreskes, N., Doran, P.T., Anderegg, W.R.L., Verheggen, B., Maibach, E.W., Carlton, J.S., Lewandowsky, S., Skuce, A.G., Green, S.A., Nuccitelli, D., Jacobs, P., Richardson, M., Winkler, B., Painting, R., \& Rice, K. (2016). Consensus on consensus: a synthesis of consensus estimates on humancaused global warming. Environmental Research Letters, 11(4), 048002.

D’Amato, D., Droste, N., Allen, B., Kettunen, M., Lähtinen, K., Korhonen, J., Leskinen, P., Matthies, B.D., \& Toppinen, A. (2017). Green, circular, bio economy: a comparative analysis of sustainability avenues. Journal of Cleaner Production, 168, 716-734.

D’Amato, D., Droste, N., Winkler, K.J., \& Toppinen, A. (2019). Thinking green, circular or bio: eliciting researchers' perspectives on a sustainable economy with Q method. Journal of Cleaner Production, 230, 460-476.

Day, C., \& Parnell, R. (2003). Consensus design: socially inclusive process. Routledge. Burlington.

EASAC. (2016). Circular economy: indicators and priorities for critical materials. https://easac.eu/publications/details/circular-economy-indicators-and-priorities-for-critical-materials/

El Alaoui, M. (2018). SMART grid evaluation using fuzzy numbers and TOPSIS. IOP Conference Series: Materials Science and Engineering, 353(1), 012019. Fez Meknes, Morocco.

El Alaoui, M., \& Ben-azza, H. (2017a). Aggregation of performance indicators for supply chain and fuzzy logic extensions applied to green supply chain. 2017 International Colloquium on Logistics and Supply Chain Management (LOGISTIQUA), 36-41. Rabat, Morocco.

El Alaoui, M., \& Ben-azza, H. (2017b). Generalization of the weighted product aggregation applied to data fusion of intuitionistic fuzzy quantities. 2017 Intelligent Systems and Computer Vision, 1-6. Fez, Morocco.

El Alaoui, M., Ben-azza, H., \& El Yassini, K. (2019a). Achieving consensus in interval valued intuitionistic fuzzy environment. Procedia Computer Science, 148, 218-225. https://doi.org/10.1016/j.procs.2019.01.064

El Alaoui, M., Ben-Azza, H., Zahi, A. (2018). New multi-criteria decision-making based on fuzzy similarity, distance and ranking. In: Abraham, A., Haqiq, A., Ella Hassanien, A., Snasel, V., Alimi, A. (eds) Proceedings of the Third International Afro-European Conference for Industrial Advancement AECIA 2016. AECIA 2016. Advances in Intelligent Systems and Computing, vol 565. Springer, Cham. Doi: 10.1007/978-3-319-60834-1_15.

El Alaoui, M., El Yassini, K., \& Ben-azza, H. (2019b). Type 2 fuzzy TOPSIS for agriculture MCDM problems. International Journal of Sustainable Agricultural Management and Informatics, 5(2-3), 112 130.

Ellis, E.C. (2018). Anthropocene: a very short introduction (Vol. 558). Oxford University Press. United Kingdom.

Farooque, M., Zhang, A., Thürer, M., Qu, T., \& Huisingh, D. (2019). Circular supply chain management: a definition and structured literature review. Journal of Cleaner Production, 228, 882-900. 
International Journal of Mathematical, Engineering and Management Sciences

Vol. 5, No. 6, 1118-1127, 2020

https://doi.org/10.33889/IJMEMS.2020.5.6.085

Ferreira Gregorio, V., Pié, L., \& Terceño, A. (2018). A systematic literature review of bio, green and circular economy trends in publications in the field of economics and business management. Sustainability, 10(11), 4232.

Figge, F., Thorpe, A.S., Givry, P., Canning, L., \& Franklin-Johnson, E. (2018). Longevity and circularity as indicators of eco-efficient resource use in the circular economy. Ecological Economics, 150, 297-306.

Fuller, R.J. (2010). Beyond cliché-reclaiming the concept of sustainability. Australian Journal of Environmental Education, 26, 7-18.

Geng, Y., Fu, J., Sarkis, J., \& Xue, B. (2012). Towards a national circular economy indicator system in China: an evaluation and critical analysis. Journal of Cleaner Production, 23(1), 216-224.

Geng, Y., Sarkis, J., Ulgiati, S., \& Zhang, P. (2013). Measuring china's circular economy. Science, 339(6127), 1526-1527.

Giddings, B., Hopwood, B., \& O’Brien, G. (2002). Environment, economy and society: fitting them together into sustainable development. Sustainable Development, 10(4), 187-196.

Herrera-Viedma, E., Cabrerizo, F.J., Kacprzyk, J., \& Pedrycz, W. (2014). A review of soft consensus models in a fuzzy environment. Information Fusion, 17, 4-13.

Howard, M., Hopkinson, P., \& Miemczyk, J. (2019). The regenerative supply chain: A framework for developing circular economy indicators. International Journal of Production Research, 57(23), 7300 7318

Hu, J., Xiao, Z., Zhou, R., Deng, W., Wang, M., \& Ma, S. (2011). Ecological utilization of leather tannery waste with circular economy model. Journal of Cleaner Production, 19(2), 221-228.

Jørgensen, S., \& Pedersen, L.J.T. (2018). The circular rather than the linear economy. In: Jørgensen. S., \& Pedersen, L.J.T (eds.), RESTART Sustainable Business Model Innovation (pp. 103-120). Palgrave Macmillan, Cham.

Kirchherr, J., Reike, D., \& Hekkert, M. (2017). Conceptualizing the circular economy: an analysis of 114 definitions. Resources, Conservation and Recycling, 127, 221-232.

Lee, H.S. (2002). Optimal consensus of fuzzy opinions under group decision making environment. Fuzzy Sets and Systems, 132(3), 303-315.

Lehrer, K., \& Wagner, C. (1981). Rational consensus in science and society: a philosophical and mathematical study (Vol. 24). Springer Netherlands.

Lopes de Sousa Jabbour, A.B., Rojas Luiz, J.V., Rojas Luiz, O., Jabbour, C.J.C., Ndubisi, N.O., Caldeira de Oliveira, J.H., \& Junior, F.H. (2019). Circular economy business models and operations management. Journal of Cleaner Production, 235, 1525-1539.

López-Ortega, O., \& Castro-Espinoza, F. (2019). Fuzzy similarity metrics and their application to consensus reaching in group decision making. Journal of Intelligent \& Fuzzy Systems, 36(4), 30953104. https://doi.org/10.3233/JIFS-18508

Molina-Sánchez, E., Leyva-Díaz, J.C., Cortés-García, F.J., \& Molina-Moreno, V. (2018). Proposal of sustainability indicators for the waste management from the paper industry within the circular economy model. Water, 10(8), 1014.

Potting, J., Hekkert, M.P., Worrell, E., \& Hanemaaijer, A. (2017). Circular economy: measuring innovation in the product chain (No. 2544). PBL Publishers.

Prieto-Sandoval, V., Jaca, C., \& Ormazabal, M. (2018). Towards a consensus on the circular economy. Journal of Cleaner Production, 179, 605-615. 
International Journal of Mathematical, Engineering and Management Sciences

Vol. 5, No. 6, 1118-1127, 2020

https://doi.org/10.33889/IJMEMS.2020.5.6.085

Roth, A.V., Schroeder, R.G., Kristal, M.M., \& Huang, X. (2008). Handbook of metrics for research in operations management: multi-item measurement scales and objective items. SAGE. California.

Sihvonen, S., \& Ritola, T. (2015). Conceptualizing ReX for aggregating end-of-life strategies in product development. Procedia CIRP, 29, 639-644.

Smol, M., Kulczycka, J., \& Avdiushchenko, A. (2017). Circular economy indicators in relation to ecoinnovation in European regions. Clean Technologies and Environmental Policy, 19(3), 669-678.

Tantau, A.D., Maassen, M.A., \& Fratila, L. (2018). Models for analyzing the dependencies between indicators for a circular economy in the European union. Sustainability, 10(7), 2141.

Wu, D., \& Mendel, J.M. (2009). A comparative study of ranking methods, similarity measures and uncertainty measures for interval type-2 fuzzy sets. Information Sciences, 179(8), 1169-1192.

Xuan, L.I., Baotong, D.E.N.G., \& Hua, Y.E. (2011). The research based on the 3-R principle of agro-circular economy model-the Erhai lake basin as an example. Energy Procedia, 5, 1399-1404.

Zadeh, L.A. (1965). Fuzzy sets. Information and Control, 8(3), 338-353.

Zhao, H., Zhao, H., \& Guo, S. (2017). Evaluating the comprehensive benefit of eco-industrial parks by employing multi-criteria decision making approach for circular economy. Journal of Cleaner Production, 142, 2262-2276. 